\title{
A 12-month feasibility study to investigate the effectiveness of cryogen-cooled monopolar radiofrequency treatment for female stress urinary incontinence
}

Bruce B. Allan, PhD, MD, FRCS(C $)^{1}$; Stacie Bell, $\mathrm{PhD}^{2}$; Kathryn Husarek, $\mathrm{PhD}^{2}$

${ }^{1}$ Allan Centre, Calgary, Alberta, Canada; ${ }^{2}$ Viveve Inc., United States

Funding: The study was funded within the Allan Centre and supported as part of the Viveve Investigator-Sponsored Research Program (which also provided study supplies and administrative assistance).

Cite as: Can Urol Assoc J 2020 February 4; Epub ahead of print. http://dx.doi.org/10.5489/cuaj.6145

Published online February 4, 2020

$* * *$

\section{Abstract}

Introduction: The purpose of this early feasibility study was to evaluate the safety and efficacy of a non-ablative, cryogen-cooled, monopolar radiofrequency (CMRF) treatment for female stress urinary incontinence (SUI).

Methods: Subjects meeting all the inclusion and exclusion criteria were enrolled and randomized into two groups. Subjects in Group 1 received one CMRF treatment and subjects in Group 2 received two CMRF treatments six weeks apart. Followup visits were performed at one, four, six, and 12 months post-treatment. At each study visit, subjects performed an objective, standardized one-hour pad weight test and completed several patient-reported outcome measures, a seven-day bladder voiding diary, and safety assessments.

Results: Data indicate an improvement in SUI symptoms and quality of life for subjects, as determined by validated SUI-related patient-reported outcomes and the objective one-hour pad weight test, with a $>50 \%$ reduction in pad weight from baseline for $52 \%$ of the subjects at 12 months. In addition to efficacy, the CMRF treatment was well-tolerated and safe.

Conclusions: The outcome measures evaluated indicate an improvement in SUI symptoms and quality of life. The sustained benefit of the CMRF vaginal treatment at 12 months suggests potential use as an office-based, non-surgical approach to treat mild to moderate SUI. 


\section{Introduction}

According to the International Continence Society, urinary incontinence is defined as the involuntary loss of urine. The two major types of female urinary incontinence are urge urinary incontinence (UUI) and stress urinary incontinence (SUI). SUI is the involuntary loss of urine with effort, force or physical exertion including exercise, or on sneezing or coughing. SUI is the most prevalent type of UI in women ${ }^{1}$ but in reality, many women have a mixed presentation.

SUI is a common affliction in women. According to the American Urogynecologic Society (AUGS), SUI affects one in three women over 45 years old. ${ }^{2}$ Pregnancy, childbirth, obesity, and menopause are all common contributors of SUI. ${ }^{3}$ More than half of women who have had a vaginal childbirth will show symptoms of SUI and are more likely to develop long-term SUI when compared to cesarean delivery. ${ }^{4}$ Furthermore, SUI has significant impacts on a woman's health and quality of life. ${ }^{5}$ Some women may choose to avoid social gatherings, physical exercise, travel, and sexual intercourse depending on the severity of incontinence. ${ }^{6,7}$

Although various treatments exist for women suffering from SUI, the current options have limitations. Conservative treatment options include: "watching and waiting" to see if SUI worsens, diet/exercise changes ${ }^{1}$ and pelvic floor muscle training (PFMT). Some women may find benefit from these therapies ${ }^{8}$, but long-term compliance and sustainability are difficult. ${ }^{9}$ While pharmacologic intervention ${ }^{10}$ or injectable bulking agents ${ }^{11,12}$ offer additional semi-conservative treatment options, they may pose efficacy or safety issues ${ }^{13}$ and usually do not offer a permanent solution. Current surgical options exist (e.g., mesh or sling placement) with proven success rates ${ }^{14}$, however, complications of mesh surgery can and have occurred, negatively impacting patients. Due to these negative impacts, some countries, including: the United Kingdom ${ }^{15}$, New Zealand ${ }^{16}$ and Austrailia ${ }^{17}$, have banned the use of surgical mesh to treat SUI. The gap between conservative and highly invasive, surgical treatment options presents an opportunity to provide more effective and non-surgical treatments for women suffering from mild to moderate SUI.

In an effort to provide new treatment options, office-based procedures with energy-based devices, such as laser and radiofrequency devices, for treating women's intimate health issues (e.g., SUI, vaginal atrophy/GSM, vaginal laxity) are occurring more frequently. ${ }^{18-21}$ Radiofrequency (RF) energy has previously been used to treat various epithelial tissues including pharynx, skin, cornea, and vagina for a variety of patient conditions, including SUI. ${ }^{22}$ Earlier RF devices that were FDA cleared to treat SUI utilized transvaginal surgery or transurethral probes with hooks in the bladder to deliver the RF energy. ${ }^{23,24}$ However, due to patient safety concerns, these RF devices are no longer commercially available. $^{23-25}$

In contrast, another monopolar radiofrequency device with cryogen-cooling (CMRF) has a welldocumented safety profile and has previously been used to effectively treat vaginal laxity and sexual dysfunction ${ }^{26,27}$ The device delivers monopolar RF energy vaginally through an external probe deep into the lamina propria layer of vaginal tissue while using cryogen cooling to protect the upper mucosal layer. Recently, a small 10-patient pilot study using CMRF to treat women with SUI reported a $>90 \%$ 
improvement from baseline in SUI symptoms and quality of life as reported by SUI-related questionnaires after 12 months of treatment. Following those positive subjective results, this larger investigator-initiated early feasibility study was conducted to gather the first long-term, objective data on the use of CMRF to treat female SUI.

\section{Methods}

\section{Study design and research subjects}

This feasibility study was a single site, randomized, unblinded trial. Women presenting to the center with SUI were invited to participate in study screening. Following written informed consent, women completed study screening procedures which included the collection of demographic data and medical/obstetric history, and completion of the standardized 1-hour pad weight test (PWT) put forth by the International Continence Society. ${ }^{28}$ The 1 -hour PWT is a standardized series of activities (walking, coughing, climbing stairs, etc.) that the subject completes following ingestion of $500 \mathrm{~mL}$ of sodium-free liquid. Subjects were asked to wear pre-weighed pads during the assessment. The pad was weighed again at the completion of the test to determine the amount of leakage. The primary outcome of the study was the improvement in urinary incontinence as measured by the 1-hour PWT with a 30\% reduction from baseline indicating a clinically meaningful improvement. However, a more commonly used endpoint is a $>50 \%$ reduction in the 1 -hour $\mathrm{PWT}^{29,30}$, therefore that is how the data is presented. Subjects also completed several validated SUI patient reported outcome measures [Urogenital Distress Inventory-6 (UDI-6) ${ }^{31}$, Incontinence Impact Questionnaire-Short Form (IIQ-7) ${ }^{31}$, and International Consultation on Incontinence Modular Questionnaire-Urinary Incontinence-Short Form (ICIQ-UI$\mathrm{SF})^{32}$ ]. Additionally, a site-developed 7-day bladder voiding diary, which included questions regarding leakage and daily activities, was also sent home with the subject for completion prior to randomization. The trial included females ( $\geq 18$ years of age) with a normal pelvic exam who were diagnosed with mildto-moderate SUI as defined by the 1-hour PWT (1-50 g leakage). ${ }^{28}$ Women were excluded from the trial who: were currently pregnant, had given birth $<6$ months or discontinued breast feeding $<6$ months prior to enrollment; had a condition/illness that might confound the results of urinary incontinence assessment including: an abnormal pelvic exam, greater than stage II pelvic organ prolapse, or were morbidly obese; had a history of genital fistula or a thin recto-vaginal septum $(\leq 2 \mathrm{~cm})$; had a previous energy-based device treatment in the genitourinary area; and/or were taking any new medication that affects urination. Subjects returned to the center for follow up visits at 1, 4, 6, and 12 months post-treatment. The 1-hr PWT, 7-day bladder voiding diary, and subjective questionnaires (UDI-6, IIQ-7, and ICIQ-UI-SF) were completed at each follow up visit. Adverse events and concomitant medications were collected at each of the follow-up visits. Any subjects who did not complete the study and were lost to follow-up were excluded from the analysis in future timepoints. 


\section{Randomization and intervention}

Subjects meeting the inclusion and exclusion criteria were randomized to receive either 1 or $2 \mathrm{CMRF}$ treatments using a random number generator; odd numbers were placed into Group 1 and received 1 CMRF treatment and even numbers were placed into Group 2 and received 2 CMRF treatments. If a subject was assigned to Group 2, the second treatment occurred 6 weeks following the initial treatment. Two treatment groups and the 6 week timing between the treatments were chosen based on previous studies with other energy-based devices for SUI that require repeat treatments 4-6 weeks apart. ${ }^{18}$

This technology and its use in women with vaginal laxity and sexual disfunction consists of 110 pulses of $90 \mathrm{~J} / \mathrm{cm}^{2}$ at the introitus of the vaginal canal. ${ }^{33,34}$ The Viveve system protocol for sexual function was modified to provide additional energy to the tissue beyond the introitus for support of the urethra to improve SUI. One treatment consisted of a total of 220 pulses of $90 \mathrm{~J} / \mathrm{cm}^{2}$. The treatment area was divided into quadrants of the vaginal introitus with the area directly beneath the urethra excluded. Each quadrant was treated with five consecutive passes of five locations of pulses for a total of 25 pulses per quadrant. The remaining 20 pulses are distributed equally in quadrants 1 and 4 . As this is a minimally invasive, office-based procedure, no anesthesia is necessary during or after the treatment.

\section{Ethics}

Ethical/Institutional Review Board approval was obtained from the Health Research Ethics Board of Alberta and the study was done in compliance with Good Clinical Practices and International Conference on Harmonization (ICH) guidelines. Health Canada clearance was also obtained by Dr. Allan for this investigator-initiated study. Documentation and data management were conducted in a manner that aligns with local ethics review board guidelines.

\section{Results}

\section{Participants}

Between June and November 2017, 37 subjects were enrolled in the study. Twenty-one (21) and 14 subjects were randomized to receive one or two treatments, respectively; while two (2) subjects dropped out of the study prior to treatment. Twenty-five (25) subjects completed the 12-month follow-up visit (Figure 1). Table 1 shows the baseline characteristics for the randomized subjects. Group 2 was older (with a mean age of 46.1 years of age) than Group 1 (mean age of 41.0 years). Group 2 also had a slightly higher BMI at baseline than Group 1 ( 24.5 vs. 26.0 respectively).

\section{One-hour pad weight}

Mean leakage volumes based on the 1-hour PWT are presented in Table 2. The mean leakage volume at baseline was mild for both groups, although some women $(\mathrm{n}=10)$ with moderate incontinence, defined as $>10-50 \mathrm{~g}$ of leakage on the 1-hour PWT, were included in the trial. Baseline values did not differ greatly between treatment groups. The 12-month pad weight leakage volume was greater in Group 2 than Group 1; however, the percentage of subjects with $>50 \%$ reduction in pad weight was similar, $54 \%$ 
and $50 \%$ respectively. The cure rate, defined here as $\leq 1 \mathrm{~g}$ of leakage on the 1-hour PWT, varied between treatment groups at 12 months ( $75 \%$ for Group 1 and $54 \%$ for Group 2), as did mean change from baseline (CFB). Group 1 had a mean CFB of $-1.75 \mathrm{~g}$, while Group 2 had a mean CFB of $-4.31 \mathrm{~g}$. Three post-menopausal women were randomized into the study, all were in Group 2. Two of the 3 women were dry at 12 months based on the 1-hour PWT. To date, the previous clinical trials utilizing this CMRF technology only enrolled pre-menopausal women ${ }^{26,27}$, and the success of the CMRF treatment on these two post-menopausal women warrants further investigation and clinical studies, especially since aging and menopause are contributing factors to incontinence. ${ }^{3}$

\section{Seven-day bladder voiding diary}

Subjects reported a decrease in incontinence episodes (IEs) per day as soon as 1-month post-treatment (Table 4). Although baseline IEs vary between the groups by almost a whole episode per day, at 12 months, both groups averaged $\leq 1$ episode per day. Overall, over half (64\%) of randomized subjects report less leakage episodes compared to baseline, with most (63.5\%) reporting a $>50 \%$ reduction from baseline. Additionally, some subjects report an ability to resume strenuous physical exercise (e.g., rock climbing) after treatment.

\section{Patient-reported outcomes}

Although Group 1 had slightly higher baseline scores, there was not a significant difference between the groups at baseline. Clinically-meaningful score decreases, defined as 11 points for UDI-6 and 2.52 points for ICIQ-UI-SF, in subject's SUI symptoms and improvement in quality of life were noted on two measures (UDI-6 and ICIQ-UI-SF) as early as 1-month post-treatment ${ }^{31,32}$ (Figure 2A and 2C). IIQ-7 scores did not reach the minimal clinically important difference (MCID), defined as a 16-point reduction, until 4 months post-treatment (Figure 2B). Only UDI-6 scores met the MCID at all timepoints for both groups (Figure 2A). Although the mean composite score was decreased from baseline at 12months, both IIQ-7 and ICIQ-UI-SF mean composite scores did not meet the MCID for Group 1 at the 12-month timepoint (Figure 2B and 2C). Alternatively, Group 2 did meet the MCID for all measurements at 12-months post-treatment (Figure 2A-C).

\section{Safety}

No unanticipated or serious adverse events (SAEs) were reported in the trial. One patient reported two urinary tract infections (UTI). The first UTI occurred between the treatment visit and 1-month follow up and the second occurred between the 6-month and 12-month visits. For both UTIs, the subject was treated with 1 week of antibiotics. The investigator assessed the UTIs as unrelated to treatment.

\section{Discussion}

This feasibility study highlights the promising efficacy and safety of a CMRF procedure for the treatment of SUI. This 12-month data are a continuation on the previously published 6-month data indicating positive results of the CMRF procedure for SUI (manuscript accepted). While the results 
show continued benefit out to 12 months post-treatment for all subjects, there is a slight decrease in efficacy from 6-months. Additionally, even though there were minor differences reported between the treatment groups, the small number of subjects makes it difficult to determine any significant differences between them.

Although the percentage of women with a $>50 \%$ reduction from baseline in leakage volume at 12-months is similar between groups (50\% for Group 1 and 54\% for Group 2), the actual mean leakage volume from the 1-hour PWT differed between groups. The lower leakage volume reported from the 1hour PWT in Group 1 at 12-months could be due to a greater amount of subject dropout at 12 months. Interestingly, of the 9 women who dropped out of Group 1 before the end of the trial, 8 had improvement from baseline on the 1-hour PWT at their last measured visit; and 5 of the 9 had no leakage at all ( $0 \mathrm{~g}$ of leakage on the 1-hour PWT). In addition, when the leakage volumes at the last measured visit are considered, Group 1 has a mean CFB of $-4.81 \mathrm{~g}$ (vs. $-1.75 \mathrm{~g}$ for the subjects who completed the 12-month visit). Therefore, the population of subjects who were lost to follow up could be selective based on their positive outcomes at their last measured visit. Of note, 4 of the 9 dropouts from Group 1 were considered to have moderate SUI ( $>10-50 \mathrm{~g}$ of leakage) at baseline and 3 of these women had no leakage at their last measured timepoint.

Another difference between the groups is the average number of IEs at baseline and 12-months. While Group 1 reported lower baseline IEs (1.9 vs. 2.7 respectively), Group 2 had a bigger change from baseline. This difference could due to the unblinded nature of the study. Alternatively, Group 2 had a larger BMI than Group 1 at baseline, possibly indicating a more sedentary lifestyle, which could lead to less leakage episodes.

Additionally, many subjects met the MCID scores for the subjective SUI-related patient-reported outcome measures at 12-months. However, there are slight differences in the mean composite scores between groups, with Group 2 reporting decreased scores (over Group 1) at almost all timepoints. This could be due to a lower baseline value for Group 2; or also because this was an unblinded study, so subjects knew whether they received 1 or 2 CMRF treatments. Analysis of over 100 clinical trials showed a significant placebo effect in studies with continuous subjective outcomes, however little or no placebo effect for objective measures. ${ }^{35}$ Furthermore, based upon what is known about collagen restoration, and the CMRF system's proposed mechanism of action, including fibroblast activation and restoration of connective tissue of the lamina propria, a second CMRF treatment done at a later timepoint (e.g., 6 months vs. 6 weeks) may provide additional treatment benefits to women. A larger number of subjects, another study including a sham treatment group, a longer follow-up period, and/or a longer time between treatments may be necessary to determine the differences between one or two treatments and the optimal timing.

Although there are data to indicate that other energy-based devices are providing benefit for SUI, no other clinical trials with a monopolar radiofrequency device have demonstrated a decrease in SUI symptoms as evaluated by objective measures (1-hour pad test and voiding diary) or a sustained benefit out to 12-months post-treatment. ${ }^{22,36-39}$ Additionally, it should also be noted the CMRF system has a 


\section{Allan et al \\ Cryogen-cooled monopolar radiofrequency for SUI}

well-documented safety profile. Thousands of women have been treated globally for sexual dysfunction and data from these clinical trials reported only mild adverse events. ${ }^{26,33,34}$ Additionally, recent ovine studies have confirmed tissue temperatures that would result in cellular responses related to the observed clinical outcomes with no thermal damage to the vaginal tissue following multiple pulses in the same area (Viveve internal data).

\section{Conclusions}

While this paper summarizes data from an investigator-initiated feasibility study, the results include the first 12-month objective outcome data for a vaginal CMRF procedure for the treatment of SUI. In this trial, there was no benefit to a second CMRF treatment at 6 weeks. However, this CMRF procedure shows promise as another option for patients searching for more-effective and non-surgical treatments for SUI. This preliminary study merits a larger scale, randomized, blinded, and sham-controlled clinical trial to investigate this procedure for the treatment of SUI. Additional studies to investigate optimal timing between procedures is also warranted. 


\section{References}

1. Markland AD, Richter HE, Fwu CW, Eggers P, Kusek JW. Prevalence and trends of urinary incontinence in adults in the United States, 2001 to 2008. J Urol. 2011;186(2):589-93.

2. Stress Urinary Incontinence. Americal Urogynecologic Society wwwvoicesforpfdorg. 2016.

3. Aoki Y, Brown, H. W., Brubaker, L., Cornu, J. N., Daly, J. O., Cartwright, R. Urinary incontinence in women. Nat Rev Dis Primers. 2017;3:17042.

4. Tahtinen RM, Cartwright, R., Tsui, J. F., et. al. . Long-term Impact of Mode of Delivery on Stress Urinary Incontinence and Urgency Urinary Incontinence: A Systematic Review and Meta-analysis. Eur Urol. 2016;70(1):148-58.

5. Saarni SI. The impact of 29 chronic conditions on health-related quality of life: a general population survey in Finland using 15D and EQ5D. Qual Life Res. 2006;15:1403-14.

6. Salonia A. Sexual dysfunction is common in women with lower urinary tract symptoms and urinary incontinence: results of a cross-sectional study. Eur Urol. 2004;45:642-8.

7. Yip SK. The impact of urodynamic stress incontinence and detrusor overactivity on marital relationship and sexual function. . Am J Obstet Gynecol. 2003;188:1244-8.

8. Guralnick ML, Kelly H, Engelke H, Koduri S, O'Connor RC. InTone: a novel pelvic floor rehabilitation device for urinary incontinence. Int Urogynecol J. 2015;26(1):99-106.

9. Beyar NG, A. . Pelvic floor muscle training for female stress urinary incontinence: five years outcomes. . Neurourol Urodyn. 2015;36:132-5.

10. Norton PA, Zinner NR, Yalcin I, Bump RC. Duloxetine versus placebo in the treatment of stress urinary incontinence. Am J Obstet Gynecol. 2002;187(1):40-8.

11. Toozs-Hobson P, Al-Singary W, Fynes M, Tegerstedt G, Lose G. Two-year follow-up of an open-label multicenter study of polyacrylamide hydrogel (Bulkamid(R)) for female stress and stress-predominant mixed incontinence. Int Urogynecol J. 2012;23(10):1373-8.

12. Urethral Bulking for Stress Urinary Incontinence. Americal Urogynecologic Society wwwvoicesforpfdorg. 2018.

13. Kerr LA. Bulking Agents in the Treatment of Stress Urinary Incontinence: History, Outcomes, Patient Populations, and Reimbursement Profile. Reviews in Urology. 2005;7(Suppl 1):S3-S11.

14. Ford AA, Rogerson, L., Cody, J. D. \& Ogah, J. Midurethral sling operations for stress urinary incontinence in women. . Cochrane Database Syst Rev. 2015;7:CD006375.

15. Review TIMMDS. Independent Review calls for immediate halt of the use of surgical mesh for stress urinary incontinence. Available at: http://www.immdsreview.org.uk/news.html.

16. Health Mo. Medsafe introduces sugical mesh restictions. Available at: https://www.health.govt.nz/news-media/media-releases/medsafe-introduces-surgical-meshrestrictions.

17. Administration DoHTG. TGA actions after review into urogynaecolical surgical mesh implants. Available at: https://www.tga.gov.au/alert/tga-actions-after-reviewurogynaecological-surgical-mesh-implants\#actions.

18. Ogrinc UB, Sencar S, Lenasi H. Novel minimally invasive laser treatment of urinary incontinence in women. Lasers Surg Med. 2015;47(9):689-97. 
19. Tien YW, Hsiao SM, Lee CN, Lin HH. Effects of laser procedure for female urodynamic stress incontinence on pad weight, urodynamics, and sexual function. Int Urogynecol J. 2017;28(3):469-76.

20. Cruz VL, Steiner ML, Pompei LM, et al. Randomized, double-blind, placebo-controlled clinical trial for evaluating the efficacy of fractional CO2 laser compared with topical estriol in the treatment of vaginal atrophy in postmenopausal women. Menopause. 2018;25(1):21-8.

21. Sokol ER, Karram MM. Use of a novel fractional CO2 laser for the treatment of genitourinary syndrome of menopause: 1-year outcomes. Menopause. 2017;24(7):810-4.

22. Lordelo P, Vilas Boas A, Sodre D, Lemos A, Tozetto S, Brasil C. New concept for treating female stress urinary incontinence with radiofrequency. Int Braz J Urol. 2017;43(5):896902.

23. Dmochowski R, Appell RA. Advancements in Minimally Invasive Treatments for Female Stress Urinary Incontinence: Radiofrequency and Bulking Agents. Current Urology Reports. 2003;4:350-5.

24. Appell RA, Juma S, Wells WG, et al. Transurethral radiofrequency energy collagen microremodeling for the treatment of female stress urinary incontinence. Neurourol Urodyn. 2006;25(4):331-6.

25. Appell RA. Transurethral Collagen Denaturation for Women With Stress Urinary Incontinence. Current Urology Reports. 2008;9:373-9.

26. Krychman M, Rowan, C. G., Allan, B. B., DeRogatis, L., Durbin, S., Yacoubian, A., Wilkerson, D. Effect of Single-Treatment, Surface-Cooled Radiofrequency Therapy on Vaginal Laxity and Female Sexual Function: The VIVEVE I Randomized Controlled Trial. J Sex Med. 2017;14(2):215-25.

27. Krychman M, Rowan CG, Allan BB, Durbin S, Yacoubian A, Wilkerson D. Effect of Single-Session, Cryogen-Cooled Monopolar Radiofrequency Therapy on Sexual Function in Women with Vaginal Laxity: The VIVEVE I Trial. J Womens Health (Larchmt). 2017.

28. Krhut J, Zachoval R, Smith PP, et al. Pad weight testing in the evaluation of urinary incontinence. Neurourol Urodyn. 2014;33(5):507-10.

29. P. Abrams JGB, S.L. Stanton, J.T. Anderson. . The standardization of terminology of lower urinary tract function. Scand J Urol Nephrol Suppl. 1988;144:5-19.

30. FDA. Guidance for Industry and Food and Drug Administration Staff Clinical Investigations of Devices Indicated for the Treatment of Urinary Incontinence. 2011.

31. Uebersax J.S. W, J.F., Shumaker, S.A., McClish, D.K., Andrew Fantl, J., and the Continence Program for Women Research Group. Short Forms to Assess Life Quality and Symptom Distress for Urinary Incontinence in Women: The Incontinence Impact Questionnaire and the Urogenital Distress Inventory. Neurourol Urodyn. 1995;14:131-9.

32. Avery K, Donovan, J., Peters, T. J., Shaw, C., Gotoh, M., Abrams, P. ICIQ: a brief and robust measure for evaluating the symptoms and impact of urinary incontinence. Neurourol Urodyn. 2004;23(4):322-30.

33. Sekiguchi Y, Utsugisawa Y, Azekosi Y, et al. Laxity of the vaginal introitus after childbirth: nonsurgical outpatient procedure for vaginal tissue restoration and improved sexual satisfaction using low-energy radiofrequency thermal therapy. J Womens Health (Larchmt). 2013;22(9):775-81. 
34. Millheiser LS, Pauls RN, Herbst SJ, Chen BH. Radiofrequency treatment of vaginal laxity after vaginal delivery: nonsurgical vaginal tightening. J Sex Med. 2010;7(9):3088-95.

35. ASBJØRN HRÓBJARTSSON PCG. IS THE PLACEBO POWERLESS? An Analysis of Clinical Trials Comparing Placebo with No Treatment. N Engl J Med.344(21):1594-602.

36. Caruth J. Evaluation of the Safety and Efficacy of a Novel Radiofrequency Device for Vaginal Treatment. Surg Technol Int.32.

37. Lalji S, Lozanova P. Evaluation of the safety and efficacy of a monopolar nonablative radiofrequency device for the improvement of vulvo-vaginal laxity and urinary incontinence. J Cosmet Dermatol. 2017;16(2):230-4.

38. Leibaschoff G GIP, Cardona JL, Miklos JR, Moore RD. Transcutaneous Temperature Controlled Radiofrequency (TTCRF) for the Treatment of Menopausal Vaginal/Genitourinary Symptoms. Surg Technol Int. 2016;Oct 26(XXIX):149-59.

39. F. V, M. R. Technological evolution in the radiofrequency treatment of vaginal laxity and menopausal vulvo-vaginal atrophy and other genitourinary symptoms: first experiences with a novel dynamic quadripolar device. 2016.

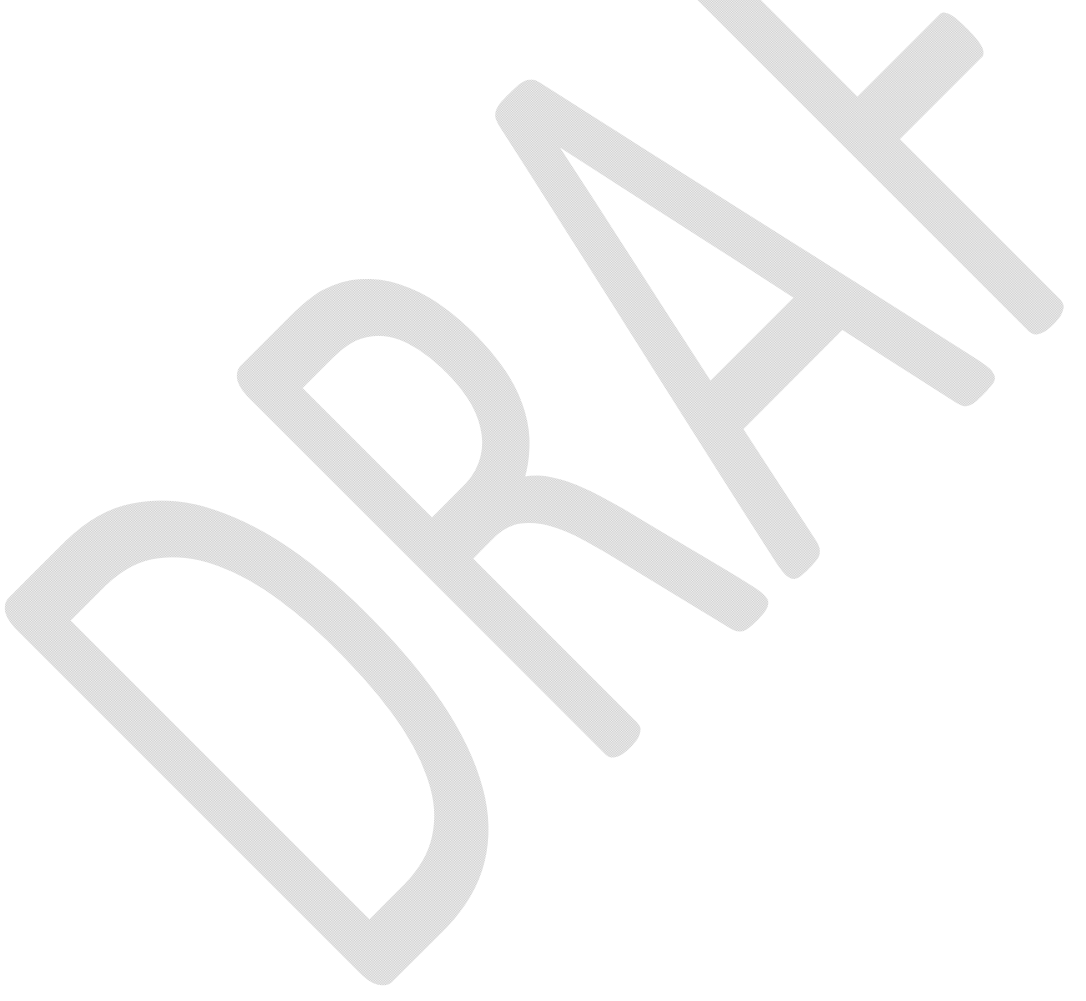


Figures and Tables

Fig.1. Patient disposition.

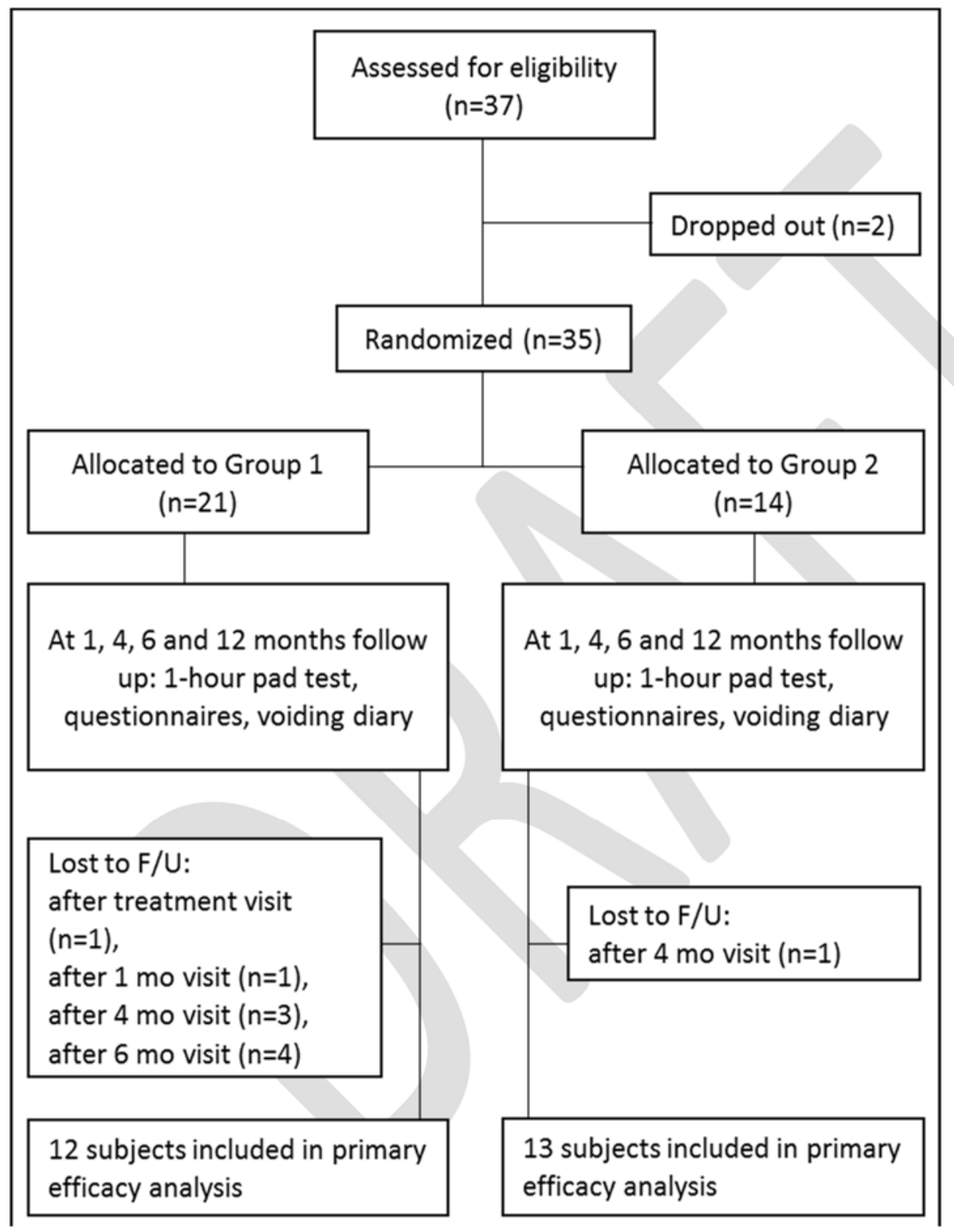


Fig. 2. Mean composite scores for stress urinary incontinence (SUI)-related patient-reported outcomes. ICIQ-UI-SF: International Consultation of Incontinence Questionnaire - Short Form; IIQ: Incontinence Impact Questionnaire; UDI: Urinary Distress Inventory.

Figure 2. SUI-related Patient Reported Outcomes
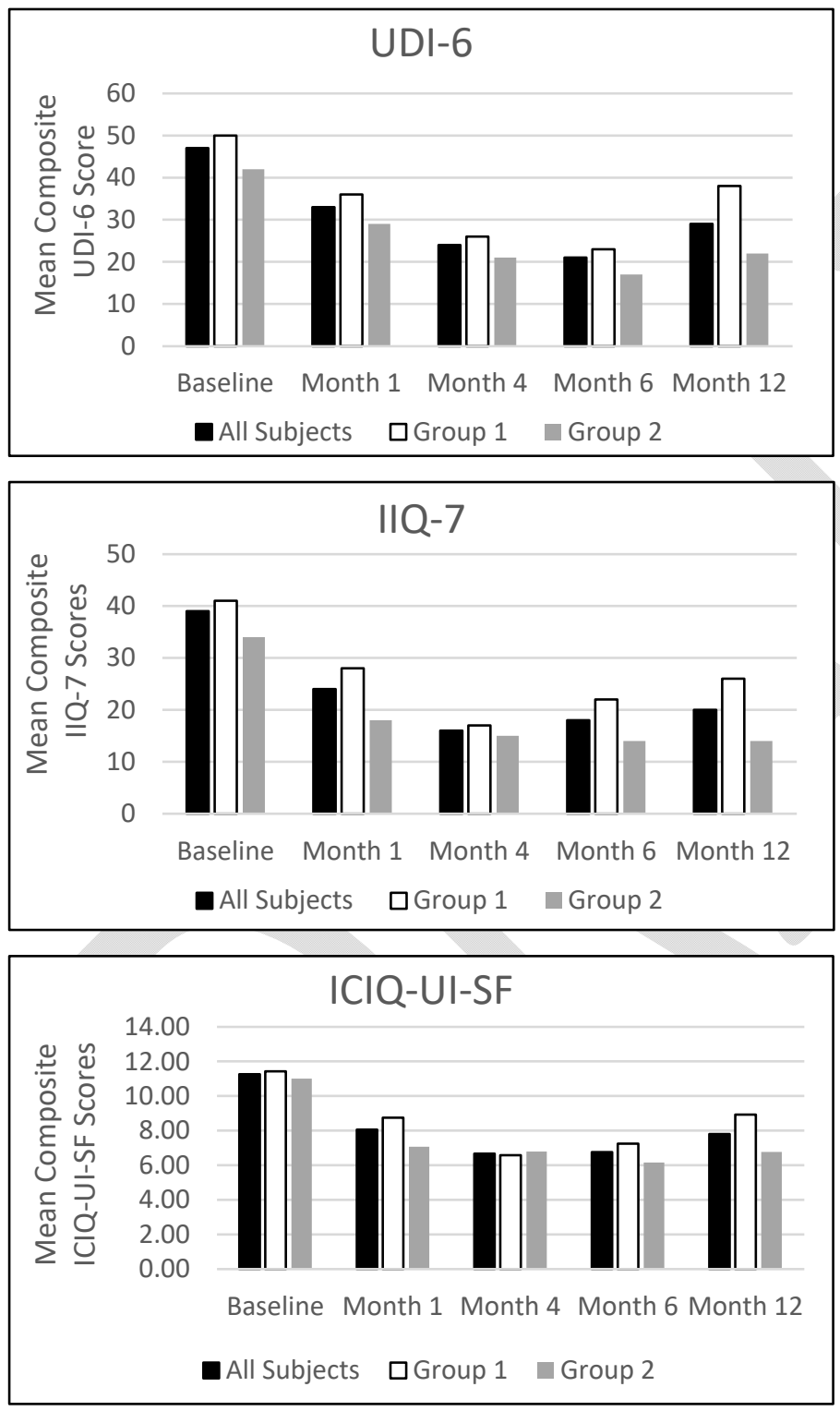


\begin{tabular}{|c|c|c|c|c|}
\hline & \multicolumn{2}{|c|}{ Group 1} & \multicolumn{2}{|c|}{ Group 2} \\
\hline No. of subjects & \multicolumn{2}{|c|}{21} & \multicolumn{2}{|c|}{14} \\
\hline Demographic data & Mean & SD & Mean & SD \\
\hline Age & 41.0 & 4.6 & 46.1 & 9.2 \\
\hline Age categories & $\mathbf{n}$ & $\%$ & $\mathbf{n}$ & $\%$ \\
\hline$<35$ years & 3 & $14.3 \%$ & 2 & $14.3 \%$ \\
\hline $35-39$ years & 5 & $23.8 \%$ & 1 & $7.1 \%$ \\
\hline 40-44 years & 6 & $28.5 \%$ & 4 & $28.5 \%$ \\
\hline$\geq 45$ years & 7 & $33.3 \%$ & 7 & $50.0 \%$ \\
\hline Clinical data & Mean & SD & Mean & SD \\
\hline BMI & 24.5 & 4.4 & 26.0 & 4.5 \\
\hline BMI categories & $\mathbf{n}$ & $\%$ & $\mathbf{n}$ & $\%$ \\
\hline BMI 18.5-24.9 & 13 & $61.9 \%$ & 6 & $42.9 \%$ \\
\hline BMI 25-29.9 & 5 & $23.8 \%$ & 6 & $42.9 \%$ \\
\hline $\mathrm{BMI} \geq 30$ & 3 & $14.3 \%$ & 2 & $14.3 \%$ \\
\hline Maternal history & Mean & SD & Mean & SD \\
\hline No. of pregnancies & 2.0 & 1.2 & 2.3 & 0.8 \\
\hline No. of full-term deliveries & 1.7 & 1.0 & 2.3 & 0.7 \\
\hline No. of vaginal deliveries & 1.5 & 1.0 & 2.0 & 1.0 \\
\hline Race & n & $\%$ & $\mathbf{n}$ & $\%$ \\
\hline White & 20 & $95.2 \%$ & 14 & $100 \%$ \\
\hline Asian & 1 & $4.8 \%$ & 0 & $0.0 \%$ \\
\hline
\end{tabular}

SD: standard deviation.

\begin{tabular}{|l|c|c|c|c|c|c|c|c|c|c|c|c|c|c|c|}
\hline \multicolumn{1}{|c|}{ Table 2. Mean leakage volume on the 1-hour PWT at 1, 4, 6-, and 12-month followup visits } \\
\hline & \multicolumn{3}{|c|}{ Baseline } & \multicolumn{3}{c|}{ Month 1 } & \multicolumn{3}{c|}{ Month 4 } & \multicolumn{3}{c|}{ Month 6 } & \multicolumn{3}{c|}{ Month 12 } \\
\hline Group & $\mathbf{n}$ & Mean & SD & $\mathbf{n}$ & Mean & SD & n & Mean & SD & n & Mean & SD & n & Mean & SD \\
\hline $\begin{array}{l}\text { All } \\
\text { subjects }\end{array}$ & 35 & 7.29 & 7.5 & 34 & 2.15 & 2.4 & 33 & 1.27 & 1.8 & 29 & 1.69 & 2.5 & 25 & 3.20 & 4.6 \\
\hline Group 1 & 21 & 7.24 & 8.1 & 20 & 2.25 & 2.6 & 19 & 1.11 & 1.6 & 16 & 1.81 & 3.0 & 12 & 2.83 & 4.6 \\
\hline Group 2 & 14 & 7.36 & 6.8 & 14 & 2.00 & 2.1 & 14 & 1.50 & 2.1 & 13 & 1.54 & 1.8 & 13 & 3.54 & 4.8 \\
\hline
\end{tabular}

PWT: pad weight test; SD: standard deviation. 


\begin{tabular}{|c|c|c|c|c|c|c|c|c|c|c|}
\hline \multirow[b]{3}{*}{ Group } & \multicolumn{8}{|c|}{$\begin{array}{c}\text { Percentage of subjects with a }>50 \% \text { reduction in pad } \\
\text { weight from baseline }\end{array}$} & \multicolumn{2}{|c|}{$\begin{array}{c}\text { Cure rate } \\
(\leq 1 \text { g leak })\end{array}$} \\
\hline & \multicolumn{2}{|c|}{ Month 1} & \multicolumn{2}{|c|}{ Month 4} & \multicolumn{2}{|c|}{ Month 6} & \multicolumn{2}{|c|}{ Month 12} & \multirow{2}{*}{$\begin{array}{c}\text { Month } \\
6 \\
\end{array}$} & \multirow{2}{*}{$\begin{array}{c}\text { Month } \\
12 \\
\end{array}$} \\
\hline & $\mathbf{n}$ & $\%$ & $\mathbf{n}$ & $\%$ & $\mathbf{n}$ & $\%$ & $\mathbf{n}$ & $\%$ & & \\
\hline All subjects & 34 & 56 & 33 & 73 & 29 & 69 & 25 & 52 & $66 \%$ & $60 \%$ \\
\hline Group 1 & 20 & 60 & 19 & 68 & 16 & 69 & 12 & 50 & $69 \%$ & $75 \%$ \\
\hline Group 2 & 14 & 50 & 14 & 79 & 13 & 69 & 13 & 54 & $62 \%$ & $54 \%$ \\
\hline
\end{tabular}

Table 4. Mean number of incontinence episodes at 1, 4, 6- and 12-month followup visits

\begin{tabular}{|c|c|c|c|c|c|c|c|c|c|c|c|c|c|c|c|}
\hline & \multicolumn{3}{|c|}{ Baseline } & \multicolumn{3}{|c|}{ Month 1} & \multicolumn{3}{|c|}{ Month 4} & \multicolumn{3}{|c|}{ Month 6} & \multicolumn{3}{|c|}{ Month 12} \\
\hline Group & $\mathbf{n}$ & Mean & SD & $\mathbf{n}$ & Mean & SD & $\mathbf{n}$ & Mean & SD & $\mathbf{n}$ & Mean & SD & $\mathbf{n}$ & Mean & SD \\
\hline $\begin{array}{l}\text { All } \\
\text { subjects }\end{array}$ & 35 & 2.2 & 2.4 & 34 & 1.3 & 1.9 & 32 & 1.3 & 2.1 & 28 & 1.0 & 1.9 & 25 & 0.8 & 0.8 \\
\hline Group 1 & 21 & 1.9 & 2.1 & 20 & 1.1 & 1.5 & $18^{*}$ & 1.2 & 2.1 & $15^{*}$ & 0.7 & 1.0 & 12 & 1.0 & 1.1 \\
\hline Group 2 & 14 & 2.7 & 2.8 & 14 & 1.7 & 2.4 & 14 & 1.3 & 2.3 & 13 & 1.3 & 2.5 & 13 & 0.6 & 0.5 \\
\hline
\end{tabular}

*Subject completed study visit but did not complete voiding diary.

\begin{tabular}{|c|c|c|c|c|c|c|c|c|}
\hline \multirow[b]{2}{*}{ Group } & \multicolumn{2}{|c|}{ Month 1} & \multicolumn{2}{|c|}{ Month 4} & \multicolumn{2}{|c|}{ Month 6} & \multicolumn{2}{|c|}{ Month 12} \\
\hline & $\mathbf{n}$ & $\%$ & $\mathbf{n}$ & $\%$ & $\mathbf{N}$ & $\%$ & n & $\%$ \\
\hline All subjects & 34 & 47 & 32 & 66 & 28 & 64 & 25 & 52 \\
\hline Group 1 & 20 & 45 & $18^{*}$ & 72 & $15^{*}$ & 60 & 12 & 42 \\
\hline Group 2 & 14 & 50 & 14 & 57 & 13 & 69 & 13 & 62 \\
\hline
\end{tabular}

*Subject completed study visit but did not complete voiding diary 